\title{
BRPKM
}

Buletin Riset Psikologi dan Kesehatan Mental

http://e-journal.unair.ac.id/index.php/BRPKM

e-ISSN: 2776-1851

ARTIKEL PENELITIAN

\section{Hubungan antara Dukungan Sosial dan Penyesuaian Diri pada Mahasiswa Universitas Airlangga}

\author{
HARUN AL RASYID \& ACHMAD CHUSAIRI* \\ Fakultas Psikologi Universitas Airlangga
}

\begin{abstract}
ABSTRAK
Berdasarkan penelitian-penelitian yang telah dilakukan sebelumnya didapatkan, penelitian ini akan membuktikan bahwa adanya hubungan antara dukungan sosial dengan penyesuaian diri. Variabel dukungan sosial mengacu pada teori Zimet dkk. dan variabel penyesuaian diri mengacu pada teori Baker \& Siryk. Penelitian ini merupakan penelitian kuantitatif dengan metode pengumpulan data survei. Partisipan adalah Mahasiswa Universitas Airlangga yang sedang menempuh perkuliahan. Instrumen dari penelitian ini menggunakan Multidimensional Scale of Perceived Social Support dan Student Adaptation to College Questionnaire. Hasil analisis penelitian menunjukkan bahwa hubungan yang signifikan antara dukungan sosial dengan penyesuaian diri $(r=0,486 ; \mathrm{p}=0,000)$. Dari penelitian yang telah dilakukan, dapat disimpulkan bahwa dukungan sosial dan penyesuaian diri memiliki hubungan yang positif sebesar $23,6 \%(r=0,486)$. Artinya apabila dukungan sosial mengalami peningkatan, maka penyesuaian diri juga akan mengalami peningkatan.
\end{abstract}

Kata kunci: dukungan sosial, mahasiswa, penyesuaian diri

\begin{abstract}
Based on the previous research, this research aims at investigating the relationship between social support and self-adjustment. In order to find the correlation between the two variables, the theory by Zimet et al. is used for social support, while the self-adjustment uses Baker \& Siryk. This research used a quantitative approach by applying survey as a data collection method. The participants included in this research were students of Universitas Airlangga who were currently undergoing their study. This research also used the Multidimensional Scale of Perceived Social Support and Student Adaptation to College Questionnaire as the instruments. The analysis result of this research found that there was a significant relationship between social support and self-adjustment $(r=0.486 ; p=0.000)$. This finding concludes that social support and adjustment have a positive relationship of $23,6 \%(r=0.486)$. This means that if social support increases, then self-adjustment will also increase.
\end{abstract}

Key words: self-adjustment, social support, student

Buletin Penelitian Psikologi dan Kesehatan Mental (BRPKM), 2021, Vol. 1(2), 1306-1312

Alamat kopartisipansi: Fakultas Psikologi Universitas Airlangga, Kampus B Universitas Airlangga Jalan Airlangga 4-6 Surabaya 60286. Surel: achmad.chusairi@psikologi.unair.ac.id

Naskah ini merupakan naskah dengan akses terbuka dibawah ketentuan the Creative Common Attribution License (CC-BY-4.0) (http://creativecommons.org/licenses/by/4.0), 
sehingga penggunaan, distribusi, reproduksi dalam media apapun atas artikel ini tidak dibatasi, selama sumber aslinya disitir dengan baik.

\section{PENDAHULUAN}

Mahasiswa merupakan predikat yang baru untuk siswa SMA yang memilih melanjutkan pendidikannya ke tingkat selanjutnya. Pada tahun pertama mahasiswa ini berkuliah, mereka disebut sebagai mahasiswa baru (Melly, 2008). Kemampuan menyesuaikan diri secara sosial di lingkungannya ini merupakan hal yang sangat penting. Karena apabila mereka gagal dalam menyesuiakan diri secara sosial maka dapat memberi dampak pada mahasiswa tersebut dan memutuskan untuk meninggalkan perguruan tinggi (Morgans, 2002).

Ketika individu berusaha untuk menyesuaikan diri dari SMA ke jenjang yang lebih tinggi, hal ini dapat menjadi transisi yang cukup sulit untuk sebagian besar mahasiswa. Dalam suatu studi yang telah dilakukan 20\% sampai 25\% mahasiswa baru tidak dapat menuntaskan pendidikan pada tahun selanjutnya (Hamilton \& Hamilton, 2006 dalam Estiane, 2015), pada penelitian lainnya 20\% sampai $30 \%$ mahasiswa memutuskan tidak melanjutkan kuliahnya di tahun setelahnya, hal tersebut dapat dikarenakan mahasiswa yang gagal dalam menyesuaikan diri pada lingkungan yang baru ketika mahasiswa masih menjadi mahasiswa baru (Grayson, 2003 dalam Estiane, 2015).

Menurut Schneiders (dalam Rajab dkk., 2014) penyesuaian diri adalah proses dimana individu memiliki kematangan yang sudah lebih baik ketika merespon kebutuhan terhadap lingkungan yang sedang dihadapi. Penyesuaian diri akan menjadi sesuatu yang rumit untuk masing-masing individu, karena cara setiap orang ketika merespon satu kebutuhan dapat bertentangan dengan persyaratan yang ada di lingkungan individu. Konflik akan muncul ketika adanya kebutuhan internal yang saling bertentangan, dan adanya tuntutan dari eksternal yang tidak selaras ataupun terjadinya perbedaan antara kebutuhan internal dan kebutuhan eksternal (Lazarus, 1961 dalam Permatasari \& Savira, 2018).

Pada dasarnya penyesuaian yang dapat dibilang baik merupakan penyesuaian yang memiliki beberapa aspek yang dapat dilihat dari individu, misalnya dilihat dari individu memiliki pengetahuan dan pandangan untuk diri sendiri maupun orang lain; individu diterima dan menerima secara sosial di lingkungannya; memiliki perkembangan dan pengendalian diri yang baik; individu memiliki tujuan yang jelas; individu memiliki sudut pandang yang tidak berbeda dari lingkungannya; memiliki rasa humor; individu merasa memiliki tanggung jawab secara sosial; individu mampu bekerja sama dan memiliki minat terhadap orang lain; melakukan suatu pekerjaan dan bermain yang seimbang; individu mengembangkan kebiasaan yang baik; mampu beradaptasi dengan lingkungan; puas ketika menyelesaikan pekerjaan maupun bermain; lalu individu memiliki pengetahuan mengenai realitas sosial yang ada (Schneiders, 1955).

Penelitian serupa yang dilakukan oleh Saputra \& Palupi (2020) mengenai dukungan sosial yang dilakukan pada mahasiswa Universitas Airlangga yang sedang mengerjakan skripsi ditemukan hasil bahwa mayoritas mahasiswa yang memiliki dukungan sosial keluarga sebesar 53,5\%, sedangkan dukungan sosial teman sebesar $66,9 \%$ dan untuk dukungan sosial orang terdekat sebesar $61,3 \%$ Adanya dukungan sosial pada mahasiswa dapat memiliki kasadaran bahwa ketika mahasiswa merasa tertekan dan mengalami penderitaan secara emosional maka pihak yang berada disekitar mereka akan bersedia membantu (Saputra \& Palupi, 2020). Pada penelitian ini mendukung pernyataan bahwa adanya dukungan sosial pada mahasiswa membuat mereka memandang suatu masalah yang sedang mereka akan hadapi membuat mereka berkembang untuk menjadi lebih baik (Saputra \& Palupi, 2020). 
Dukungan sosial yang diungkapkan oleh House (dalam Smet, 1984) merupakan dukungan sosial yang melibatkan beberapa aspek berikut; yang terdiri dari dukungan emosional, dengan ungkapan simpati, kepedulian dan memperhatikan orang yang bersangkutan, dukungan penghargaan, dengan melalui ungkapan rasa hormat yang memiliki dampak positif bagi orang yang bersangkutan, dorongan untuk maju atau persetujuan dengan gagasan atau perasaan yang individu tersebut ajukan, dan membandingkan hal-hal yang positif dari orang itu dengan orang lain, dukungan instrumental merupakan bantuan langsung untuk memudahkan individu agar mendapat pertolongan, dukungan informatif yaitu pemberian saran, nasehat ataupun dorongan yang berguna untuk individu. Sarafino \& Smith (2011) mengungkapkan bahwa dukungan sosial dapat berasal dari berbagai sumber yang ada seperti orang tua, teman, pacar, dan organisasi komunitas.

Dalam hal tersebut yang membuat peneliti memiliki keinginan dalam melakukan penelitian terkait dengan hubungan antara dukungan sosial dan penyesuaian diri pada Mahasiswa Universitas Airlangga. Berdasarkan fenomena dan literatur tersebut, peneliti tertarik untuk mengadakan penelitian tentang "Hubungan antara Dukungan sosial dan Penyesuaian Diri pada Mahasiswa Universitas Airlangga".

\section{Penyesuaian Diri}

Definisi penyesuaian diri ialah kemampuan seseorang dalam melakukan penyesuaian diri dengan lingkungan yang berada pada sekitar individu yang melibatkan respon mental serta tingkah laku yang dimana individu dapat berusaha memenuhi kebutuhan dirinya, mengatasi stres, frustasi dan hingga konflik yang dialami dalam meningkatkan keseimbangan antara kebutuhan diri individu dalam masa perkuliahan di lingkungan kampus (Baker \& Siryk, 1984). Semakin tinggi rentang skor yang diperoleh, maka akan semakin tinggi tingkat penyesuaian diri yang dimiliki. Begitu juga sebaliknya, semakin rendah rentang skor yang diperoleh, maka semakin rendah penyesuaian diri yang dimiliki. Dimensidimensi dari penyesuaian diri merupakan sebagai berikut (Baker \& Siryk, 1984):

a. Penyesuaian akademik

Penyesuaian diri secara akademik ini merupakan tugas, hasil dari pencapaian akademik dan respon ketika individu mendapatkan tugas dari perkulihan di perguruan tinggi. Perilaku ini memiliki fokus pencapaian individu secara akademik dan menjauhkan diri dari perilaku yang tidak memuaskan.

b. Penyesuaian secara emosional

Penyesuaian secara emosional merupakan perilaku dari psikologis dari individu. Kondisi ini akan berubah ketika ia mengalami situasi yang berbeda dari kebiasaan ketika individu sedang berada di lingkungan yang asing. Hal ini terkait dengan pengalaman individu saat ia mulai menjalani perkuliahan. Penyesuaian ini berkaitan dengan kondisi emosional individu, perasaan atau psikologis dari individu yang berkaitan dengan penyesuaian diri dengan lingkungan perguruan tinggi.

c. Penyesuaian sosial

Penyesuaian sosial adalah penyesuaian yang berkaitan dengan interaksi antara individu dengan orang lain yang berada di lingkungan perguruan tinggi maupun di lingkungan yang di tinggali oleh individu. Penyesuaian sosial juga meliputi bagaimana individu mampu beradaptasi dengan baik di lingkungan sekitar dan mampu menyesuaikan diri dengan baik.

d. Kelekatan dengan institusi 
Kelekatan dengan intitusi dimana individu merasa memimiliki kelekatan dengan suatu institusi yang sedang ia masuki. Kelekatan akan diketahui apabila adanya interaksi antara kelekatan dengan tujuan individu berkomitmen dengan perguruan tinggi maupun kegiatan yang ada di perguruan tinggi. Kelekatan akan menunjukkan seseorang merasa lekat dengan komitmennya agar tercapainya tujuan yang ia tetapkan di perguruan tinggi, sehingga hal ini memiliki pengaruh yang besar pada proses penyesuaian diri dari individu.

\section{Dukungan Sosial}

Definisi dukungan sosial mengacu kepada teori dari Zimet dkk. (1988) yang mendefinisikan dukungan sosial sebagai persepsi yang merupakan evaluasi subjektif tentang cukupnya dukungan sosial di lingkungan sekitarnya dalam bentuk dukungan penghargaan, emosional, instrumental, dan informasi. Definisi operasional pada penelitian ini dengan melihat total skor yang diperoleh dari alat ukur Multidimensional Scale of Perceived Social Support oleh Zimet dkk. (1988) yang terdiri atas tiga dimensi, yaitu family, friend, dan significant other. Semakin tinggi rentang skor yang didapatkan, maka akan semakin tinggi tingkat dukungan sosial yang dimiliki. Begitu juga sebaliknya, semakin rendah rentang skor yang didapatkan, maka semakin rendah dukungan sosial yang dimiliki.

\section{Desain Penelitian}

\section{METODE}

Penelitian ini menggunakan metode studi kuantitatif yang memiliki tujuan untuk menjelaskan prediksi satu variabel terhadap variabel lain, serta melakukan uji hipotesis yang telah dilakukan sebelumnya (Neuman, 2007). Tipe penelitian kuantitatif eksplanatif juga dapat digunakan untuk mengukur dan menguji hubungan sebab-akibat dari dua atau beberapa variabel (Fajarini \& Ariana, 2019).

\section{Partisipan}

Partisipan dalam penelitian ini adalah mahasiswa aktif yang sedang berkuliah di Universitas Airlangga. Dalam pengambilan data, peneliti menggunakan google form sebagai wadah untuk mengisi kuesioner oleh partisipan. Hasil dari survei yang di lakukan di google form mendapatkan partisipan sebanyak 161.

Partisipan dalam penelitian ini akan menggunakan teknik Purposive Sampling. Teknik ini dipilih karena dengan adanya karakteristik khusus, maka tidak diketahui dengan pasti jumlah spesifik dari suatu populasi. Berdasarkan penelitian Tabachnick dan Fidell (dalam Fajarini \& Ariana, 2019), jumlah sampel secara umum dapat ditentukan berdasarkan rumus $\mathrm{N}>50+8 \mathrm{~m}(\mathrm{~m}=$ variabel bebas). Penelitian ini hanya menggunakan satu variabel bebas, yaitu dukungan sosial, sehingga diperoleh rumus yakni $\mathrm{N}>50$ $+8(1)$. Maka dapat disimpulkan bahwa jumlah minimal sampel pada penelitian ini akan ideal jika mendapatkan minimal 58 partisipan. Untuk menguji hipotesis penelitian penulis menyebar skala kuisioner untuk memperoleh data dari partisipan dan mendapatkan sebanyak 161 partisipan.

\section{Pengukuran}

Alat ukur yang digunakan untuk mengukur penyesuaian diri adalah skala the student adaptation to college questionnaire yang disusun oleh Baker \& Siryk (1984). Alat ukur ini memiliki empat aspek yaitu penyesuaian akademik, penyesuaian sosial, penyesuaian emosional, kelekatan dengan institusi. Alat ukur ini menggunakan skala Likert dengan alternatif 9 pilihan jawaban dimulai dari mulai skala 1 (Sangat Tidak Sesuai) hingga skala 9 (Sangat Sesuai). Hasil uji reliabilitas diperoleh nilai ( $N=40$; $\alpha=0,945$ ) dimana reliabilitas alat ukur penelitian ini sangat baik atau reliabel. Alat ukur yang digunakan untuk mengukur dukungan sosial adalah skala multidimensional scale of perceived social support yang 
disusun oleh Zimet dkk. (1988). Alat ukur ini memiliki tiga aspek yaitu significant other, keluarga, teman. Alat ukur ini menggunakan skala Likert dengan 4 alternatif pilihan jawaban dimulai dari skala 1 (Sangat Tidak Setuju) hingga skala 4 (Sangat Setuju). Hasil uji reliabilitas diperoleh nilai $(\mathrm{N}=12 ; \alpha=0,863)$ dimana reliabilitas alat ukur penelitian ini sangat baik atau reliabel.

\section{Analisis Data}

Pada penelitian ini menggunakan teknik analisis data berupa teknik korelasi yang bertujuan untuk mengetahui hubungan antara variabel penelitian (yaitu variabel X terhadap Y). Teknik analisis data Pearson Correlation digunakan untuk menguji hipotesis pada penelitian ini yang berguna apakah data yang didapat berkolerasi atau tidak. Keseluruhan proses analisis statistik yang digunakan dalam penelitian ini menggunakan SPSS 25.0 untuk windows.

\section{HASIL PENELITIAN}

Hasil analisis statistik deskriptif pada penelitian yang telah dilakukan mendapatkan informasi statistik bahwa pada variabel dukungan sosial nilai mean sebesar 35,35 ( $S D=6,833$; Min=18; Max=48). Lalu untuk variabel penyesuaian diri memiliki nilai mean sebesar 228,06 (SD=36,644; Min=134; Max=311).

Hasil analisis uji normalitas Kolmogorov-Smirnov menunujukkan bahwa kedua variabel ini memiliki ditribusi data yang normal dapat dilihat dari nilai sig dari kedua variabel $(p>0,05)$. Dapat diketahui bahwa variabel penyesuaian diri memiliki distribusi data normal dengan nilai $(p=0,200)$. Variabel dukungan sosial memiliki distribusi data normal dengan nilai $(p=0,200)$.

Berdasarkan hasil uji korelasi diketahui bahwa dukungan sosial berkorelasi positif dan cenderung sedang $(\mathrm{r}(161)=0,486 ; p=0,000)$ dengan penyesuaian diri, hasil dari $\mathrm{R}^{2}$ menunjukan dukungan sosial memiliki hubungan dengan penyesuaian diri yang berarti $\mathrm{H}_{\mathrm{a}}$ diterima dan $\mathrm{H}_{0}$ ditolak.

\section{DISKUSI}

Tujuan dari penelitian ini adalah untuk mengetahui apakah terdapat hubungan antara dukungan sosial dengan penyesuaian diri pada mahasiswa Universitas Airlangga. Hasil dari penelitian ini dapat disimpulkan mahasiswa Universitas Airlangga yang memiliki tingkat dukungan sosial yang tergolong sangat rendah sebanyak 13 orang $(8,1 \%)$, rendah sebanyak 40 orang $(24,8 \%)$, sedang sebanyak 65 orang $(40,4 \%)$, tinggi sebanyak 33 orang $(20,5 \%)$, sangat tinggi sebanyak 10 orang $(6,2 \%)$. Sedangkan untuk variabel penyesuaian diri dengan kategori sangat rendah sebanyak 11 orang $(6,8 \%)$, rendah sebanyak 40 orang (24,8\%), sedang sebanyak 58 orang (36\%), tinggi sebanyak 43 orang (26,7\%), sangat tinggi sebanyak 9 orang $(5,6 \%)$.

Schneiders (1955) mendefinisikan penyesuaian diri merupakan proses yag terjadi ketika individu dan lingkungan yang meliputi tingkah laku dan respon mental agar individu mampu untuk menyelaraskan kedua hal ini. Pendapat yang selaras diungkapkan oleh (Haber \& Runyon, 1984) yang mendefinisikan faktor yang dapat memberikan pengaruh pada penyesuaian diri ialah kondisi fisik dari individu, keadaan psikologis, lingkungan, dan perkembangan dari individu. Apabila mahasiswa merasa tidak cukup mendapatkan kasih sayang dan dukungan dari lingkungan sosial perguruan tinggi maupun keluarganya, maka dapat mempengaruhi kondisi kesehatan mental dari pada mahasiswa tersebut. Sehingga akan menyebabkan mahasiswa penuh penyesalan, tidak nyaman berada di lingkungan perguruan tinggi, merasa tidak bahagia, ia akan memilih untuk menyendiri dan berusaha menjauh dari 
pergaulan teman sebayanya. Hal ini perlunya dukungan sosial dari orang-orang yang berada di sekitar lingkungannya.

Hasil dari penelitian ini juga menemukan adanya hubungan yang signifikan antara dukungan sosial dengan penyesuaian diri pada mahasiswa Universitas Airlangga. Hasil dari uji korelasi yang telah dilakukan pada kedua variabel menunjukkan skor koefisien korelasi sebesar 0,486 yang berarti kedua variabel memiliki hubungan yang positif dengan kekuatan yang sedang, dengan taraf signifikansi deviasi linearitas 0,090 yang memiliki arti bahwa kedua variabel ini memiliki hubungan yang linear. Besaran hubungan antara variabel dukungan sosial dan penyesuaian diri adalah senilai 0,486 . Nilai $\mathrm{R}^{2}$ dari korelasi adalah sebesar $0.486 \times 0.486=0.236$ atau $23,6 \%$. Berarti variabel dukungan sosial memiliki menjelaskan $23,6 \%$ varians variabel penyesuaian diri, 76,4\% varians variabel $Y$ dijelaskan oleh variabel lain yang tidak dimasukkan dalam analisis.

Pada penelitian tersebut juga terdapat pernyataan oleh Sarafino \& Smith (2011) yang menjelaskan ketika individu memperoleh dukungan sosial yang baik, mereka akan merasa bahwa mereka diharagai, dicintai, juga termasuk dari bagian jaringan sosial, seperti di organisasi masyarakat ataupun di keluarga. Apabila terkait penyesuaian diri pada mahasiswa yang berada dilingkungan perguruan tinggi, yaitu mahasiswa yang memiliki dukungan sosial ketika ia memasuki perguruan tinggi dan merasa bagian dari perguruan tinggi itu. Sumber dari dukungan sosial yang didapatkan oleh mahasiswa bisa bersumber dari berbagai pihak, seperti fakultas, teman sebaya, orang tua, dan senior di perguruan tinggi. Apabila mahasiswa merasa menerima dukungan sosial dari berbagai pihak ini, maka akan mempermudah proses dari penyesuaian diri yang dilakukan oleh mahasiswa yang berada dilingkungan perguruan tinggi (Sarafino \& Smith, 2011).

\section{SIMPULAN}

Hasil analisis statistik terhadap data penelitian menunjukkan adanya hubungan yang signifikan antara dukungan sosial dengan penyesuaian diri sebesar 23,6\%. Hubungan antara dukungan sosial dengan penyesuaian diri memiliki sifat yang positif namun sedang. Artinya apabila terjadi kenaikan pada dukungan sosial oleh mahasiswa Universitas Airlangga, maka akan diikuti pula kenaikan pada penyesuaian diri pada mahasiswa Universitas Airlangga. Sebaliknya, apabila adanya penurunan pada dukungan sosial akan diikuti pula penurunan oleh penyesuaian diri oleh mahasiswa Universitas Airlangga.

\section{UCAPAN TERIMAKASIH}

Segala puji bagi Tuhan Yang Maha Esa yang telah memberikan rahmat dan karunia Nya sehingga penulis dapat menyelesaikan skripsi dengan judul "Hubungan Antara Dukungan Sosial Dan Penyesuaian Diri Pada Mahasiswa Universitas Airlangga" sebagai salah satu pra syarat untuk mendapatkan gelar Sarjana Psikologi, Universitas Airlangga, Surabaya.

\section{DEKLARASI POTENSI TERJADINYA KONFLIK KEPENTINGAN}

Harun Al Rasyid dan Ahcmad Chusairi tidak bekerja, menjadi konsultan, memiliki saham, atau menerima dana dari perusahaan atau organisasi manapun yang mungkin akan mengambil untung dari diterbitkannya naskah ini. 


\section{PUSTAKA ACUAN}

Baker, R. W., \& Siryk, B. (1984). Measuring adjustment to college. Journal of Counseling Psychology, 31(2), 179-189. https://doi.org/10.1037/0022-0167.31.2.179\%0A

Estiane, U. (2015). Pengaruh Dukungan Sosial Sahabat terhadap Penyesuaian Sosial Mahasiswa Baru di Lingkungan Perguruan Tinggi. Jurnal Psikologi Klinis Dan Kesehatan Mental, 4(1), 29-40.

Fajarini, E. N., \& Ariana, A. D. (2019). Hubungan Antara Self-Efficacy Dan Health Locus of Control Dengan Intensi Berhenti Merokok Pada Emerging Adult. Jurnal Psikologi Klinis Dan Kesehatan Mental, Vol. 8/N, 76-87. http://journal.unair.ac.id/download-fullpapers-jpkk32109b5149full.pdf

Haber, A., \& Runyon, R. P. (1984). Psychology of adjustment. Homewood, Ill. : Dorsey Press, 1984.

Melly. (2008). Hubungan antara kreativitas dan stres pada mahasiswa tahun pertama Jurusan Arsitektur Universitas Indonesia. (Skripsi, Universitas Indonesia).

Morgans, K. A. (2002). The Social and Academic Adjustments of Students to College Life. National Undergraduate Research Clearinghouse, 5. http://www.webclearinghouse.net/volume/5/MORGANS-TheSociala.php

Neuman, W. L. (2007). Basics Of Social Research: Qualitative And Quantitative Approachers. New York: Pearson.

Permatasari, R. A., \& Savira, S. I. (2018). Hubungan Antara Self-Esteem Dengan Penyesuaian Diri Pada Mahasiswa Psikologi Angkatan 2017 Universitas Negeri Surabaya. Character: Jurnal Penelitian Psikologi., 5(2).

Rajab, A., Wahab, S. R. A., Shaari, R., Panatik, S. A., \& Nor, F. M. (2014). Academic and social adjustment of international undergraduates: A quantitative approach. Journal of Economics, Business and Management, 2(4), 5-8. https://doi.org/10.7763/JOEBM.2014.V2.133

Schneiders, A. A. (1955). Personal Adjustment and Mental Health. Holt, Rinehart And Winston. New York.

Saputra, M. R., \& Palupi, L. S. (2020). Relationship between Social Support and Psychological Well-Being of the Final Year Students. E3S Web of Conferences, 202, 0-5. https://doi.org/10.1051/e3sconf/202020212027

Sarafino, E. P., \& Smith, T. W. (2011). Health psychology: Biopsychosocial interactions. John Wiley \& Sons.

Smet, B. (1984). Psikologi kesehatan. Jakarta: Grasindo.

Zimet, G. D., Dahlem, N. W., Zimet, S. G., \& Farley, G. K. (1988). Multidimensional Scale Perceived Social Support. In Journal of Personality Assessment (Vol. 52, Issue 1, pp. 30-41). 